\title{
Management of hyperphosphatemia in patients with end-stage renal disease: focus on lanthanum carbonate
}

\author{
Veerle P Persy \\ Geert J Behets \\ Marc E De Broe \\ Patrick C D'Haese \\ Laboratory of Pathophysiology, \\ University of Antwerp, Belgium
}

Correspondence: Patrick C D'Haese University of Antwerp, Laboratory of Pathophysiology, Universiteitsplein I, T3.05, B-2610 Antwerp, Belgium

Tel +3238202599

Fax +32 38202592

Email patrick.dhaese@ua.ac.be

\begin{abstract}
Elevated serum phosphate levels as a consequence of chronic kidney disease (CKD) contribute to the increased cardiovascular risk observed in dialysis patients. Protein restriction and dialysis fail to adequately prevent hyperphosphatemia, and in general treatment with oral phosphate binding agents is necessary in patients with advanced CKD. Phosphate plays a pivotal role in the development of vascular calcification, one of the factors contributing to increased cardiovascular risk in CKD patients. Treatment of hyperphosphatemia with standard calcium-based phosphate binders and vitamin D compounds can induce hypercalcemic episodes, increase the $\mathrm{Ca} \times \mathrm{PO}_{4}$ product and thus add to the risk of ectopic mineralization. In this review, recent clinical as well as experimental data on lanthanum carbonate, a novel, non-calcium, non-resin phosphate binding agent are summarized. Although lanthanum is a metal cation no aluminium-like toxicity is observed since the bioavailability of lanthanum is extremely low and its metabolism differs from that of aluminium. Clinical studies now document the absence of toxic effects of lanthanum for up to 6 years of follow-up. The effects of lanthanum on bone, vasculature and brain are discussed and put in perspective with lanthanum pharmacokinetics.

Keywords: lanthanum carbonate, phosphate binding, chronic kidney disease
\end{abstract}

\section{Introduction}

Chronic kidney disease (CKD) and renal function decline are from an early stage on accompanied by disturbances in mineral metabolism, driven by increased parathyroid hormone $(\mathrm{PTH})$ secretion and decreased production of active vitamin D. Impaired phosphate excretory capacity eventually results in positive phosphate balance and hyperphosphatemia, which in combination with low serum levels of ionized calcium due to lack of vitamin D, contributes to the development of secondary hyperparathyroidism and metabolic bone disease. Chronically increased parathyroid gland stimulation may eventually lead to parathyroid gland hyperplasia and tertiary hyperparathyroidism, ie, autonomous, unregulated PTH production and secretion. ${ }^{1,2}$

The mineral phase of bone, hydroxyapatite, is the body's largest phosphate store, but inorganic phosphate, in ATP, plays an important role in cellular energy storage and phosphorylation and dephosphorylation of proteins are key events in numerous cellular singalling pathways. Serum phosphate levels above $6.5 \mathrm{mg} / \mathrm{dL}$ and elevated $\mathrm{Ca} \times \mathrm{PO}_{4}$ product in serum $\left(>72 \mathrm{mg}^{2} / \mathrm{dL}^{2}\right)$ are associated with a significantly increased mortality risk. ${ }^{3}$ Even mild increases in serum phosphate within the normal range are associated with a significant increase in mortality risk. ${ }^{4}$ Phosphate retention mainly increases cardiovascular mortality, such as death through coronary artery disease as well as sudden death. ${ }^{5}$ Disturbed phosphate metabolism is associated with increased cardiovascular mortality risk in CKD patients, and a causal role for hyperphosphatemia in the development of vascular calcification, a characteristic feature of cardiovascular disease in uremic patients, has been demonstrated both experimentally and in vitro. ${ }^{6,7}$ 
Calcification of the abdominal aorta was shown to predict subsequent cardiovascular events in hemodialysis patients ${ }^{8}$ as well as in the general population. ${ }^{9}$

\section{Treatment of hyperphosphatemia}

Dietary protein is the main source of phosphate intake, but limiting protein intake is often insufficient to prevent phosphate accumulation and the subsequent development of hyperphosphatemia. Moreover, protein restriction can contribute to malnutrition, thereby increasing the mortality risk in CKD patients. ${ }^{10,11}$ However, a recent randomized controlled trial showed significant reduction in serum phosphate with protein restriction to $0.55 \mathrm{~g} / \mathrm{kg} /$ day without increased risk for malnutrition. ${ }^{12}$ Renal replacement therapy also provides inadequate removal of the excess phosphate load in patients with end-stage renal failure, mainly because most phosphate is in the cellular compartment and exchange between the intracellular and extracellular compartments is rate-limiting. ${ }^{13,14}$ Therefore, additional treatment with phosphate binding agents is necessary in most dialysis patients, and is recommended even in CKD stages 3 and 4 when hyperphosphatemia is not under control with protein restriction. Phosphate binders are administered orally and prevent phosphate absorption from the gastrointestinal tract by forming insoluble complexes with phosphate in the gut.

The first phosphate binder, aluminium hydroxide, was introduced in the seventies. This very efficient phosphate binder was abandoned in favor of calcium-containing phosphate binders such as calcium carbonate and calcium acetate because of its significant negative effects on bone metabolism and cognitive function.

Calcium-based phosphate binders have replaced aluminium as standard phosphate binder therapy. They bind phosphate in a $\mathrm{pH}$-dependent way, with calcium acetate being more efficient than calcium carbonate. The amount of calcium absorbed per amount of phosphate bound is also lower with calcium acetate. ${ }^{15,16}$ The absorption of a substantial proportion (30\%-40\%) of the elemental calcium administered with these compounds was initially not considered to be problematic, as calcium levels tend to be low in uremic patients due to lack of active vitamin D. Low serum ionized calcium is the most important driving force for PTH secretion, thus, calcium-based binders also limit the development of secondary hyperparathyroidism.

In recent years, however, several epidemiological studies revealed an association between hypercalcemia or hypercalcemic episodes and cardiovascular mortality risk. In addition to hyperphosphatemia, hypercalcemia and elevated serum
$\mathrm{Ca} \times \mathrm{P}$ product were identified as factors contributing to the development of uremia-related vascular calcification. ${ }^{17-21}$

Although calcium-based phosphate binders are still considered the standard treatment for hyperphosphatemia in chronic and end-stage renal failure, the more recent calcium-free phosphate binders sevelamer hydrochloride and lanthanum carbonate control phosphate levels without inducing calcium overload and should be considered for patients developing hypercalcemia when given calciumbased binders.

Sevelamer hydrochloride is a non-aluminium, noncalcium-containing hydrogel of cross-linked poly-[allylamine hydrochloride] that binds phosphate anions through ionic exchange with chloride. In comparison with calcium-based phosphate binder therapy, treatment with sevelamer slowed down the progression of coronary artery and aortic calcification in dialysis patients, ${ }^{22-25}$ although Barreto et al ${ }^{26}$ did not observe this effect in the BRiC study. Apart from its phosphate binding activity, sevelamer also acts as a bile acid sequestrant, ${ }^{27}$ resulting in lowering of total and LDL cholesterol, and may induce acidosis due to exchange of bicarbonate for chloride. ${ }^{28,29}$ These non-phosphate-related effects of sevelamer may also have an impact on the vascular outcome.

In a systematic review of the efficacy and safety of established phosphate binders Sprague concluded that calcium carbonate, sevelamer hydrochloride and lanthanum carbonate are all effective as phosphate binders. Drawback of calcium carbonate is the induction of hypercalcemia, whereas sevelamer contributes to acidosis and does not bind phosphate efficiently in acidic environment. In comparison, lanthanum treatment imposes a lower pill burden, which possibly is associated with increased patient compliance. ${ }^{30}$

\section{Lanthanum pharmacokinetics}

Lanthanum is a rare earth element belonging to the 'lanthanide' elements. It is the most electropositive (cationic) element of the rare earth group, is uniformly trivalent, and almost exclusively engages in ionic binding. It is a hard 'acceptor' with an overwhelming preference for oxygen-containing anions. Therefore, the most common biological ligands are the carboxyl and phosphate groups $\left(\mathrm{PO}_{4}{ }^{3-}\right)$ with which it can form very tight complexes. These chemical characteristics form the basis for the suitability of lanthanum carbonate as a phosphate binder.

The introduction of yet another metal as a phosphate binder agent prompted concern for the potential aluminium-like toxic effects of lanthanum carbonate on bone 
and brain. However, lanthanum pharmacokinetics differ substantially from the pharmacokinetic profile of aluminium, as illustrated in Figure 1. In contrast with aluminium, accumulation of lanthanum in the context of impaired renal function is low because firstly, the absorption and bioavailibility of lanthanum are extremely low, and secondly, the very small absorbed fraction is mainly cleared via biliary excretion, with renal clearance of lanthanum being almost negligible. ${ }^{31}$

In a phase I study the absolute bioavailability of lanthanum after a single oral dose was shown to be $0.00127 \% \pm 0.00080 \%$. Renal clearance was very low following oral administration $(1.36 \pm 1.43 \mathrm{~mL} / \mathrm{min})$ amounting to $1.7 \%$ of total plasma clearance. ${ }^{32}$ The majority of an oral lanthanum dose is excreted in the feces. Biliary elimination (80\%) and direct transport across the gut wall into the lumen $(13 \%)$ represent the main routes of elimination. Therefore, the elimination of lanthanum is not dependent on renal function. So CKD patients are not at an increased risk for accumulation of the element. Moreover, lanthanum pharmacokinetics in CKD 5 patients and subjects with normal renal function were comparable. ${ }^{33}$ Plasma lanthanum is almost completely protein bound, leaving plasma concentrations of free lanthanum below $3 \mathrm{pg} / \mathrm{mL} .^{33}$

In contrast, absorption of orally administered aluminium from the gastrointestinal tract amounts from $0.01 \%$ to $0.10 \%$ (Figure 1). ${ }^{34,35}$ In addition, aluminium is mainly eliminated via the kidney, with negligible biliary excretion. When aluminium hydroxide ( $2.4 \mathrm{~g} /$ day) was co-administered with citrate, aluminium excretion increased from 70 to $120 \mathrm{mg} /$ day up to 350 to $603 \mathrm{mg} / \mathrm{day},{ }^{35}$ whereas gastro-intestinal absorption of lanthanum is not influenced by citrate.

\section{Lanthanum as a phosphate binder}

Lanthanum binds phosphate with high affinity and independent of $\mathrm{pH}$. Lanthanum is therefore able to effectively bind phosphate before it is absorbed in both the acidic environments of the stomach and proximal small intestine, as well as more distally in the gastrointestinal tract. ${ }^{36}$

In short-term placebo-controlled studies 4 weeks of treatment with lanthanum carbonate resulted in significantly lower phosphate and $\mathrm{Ca} \times \mathrm{P}$ product levels in hemodialysis and CAPD patients. ${ }^{37-39}$ Lanthanum carbonate has been
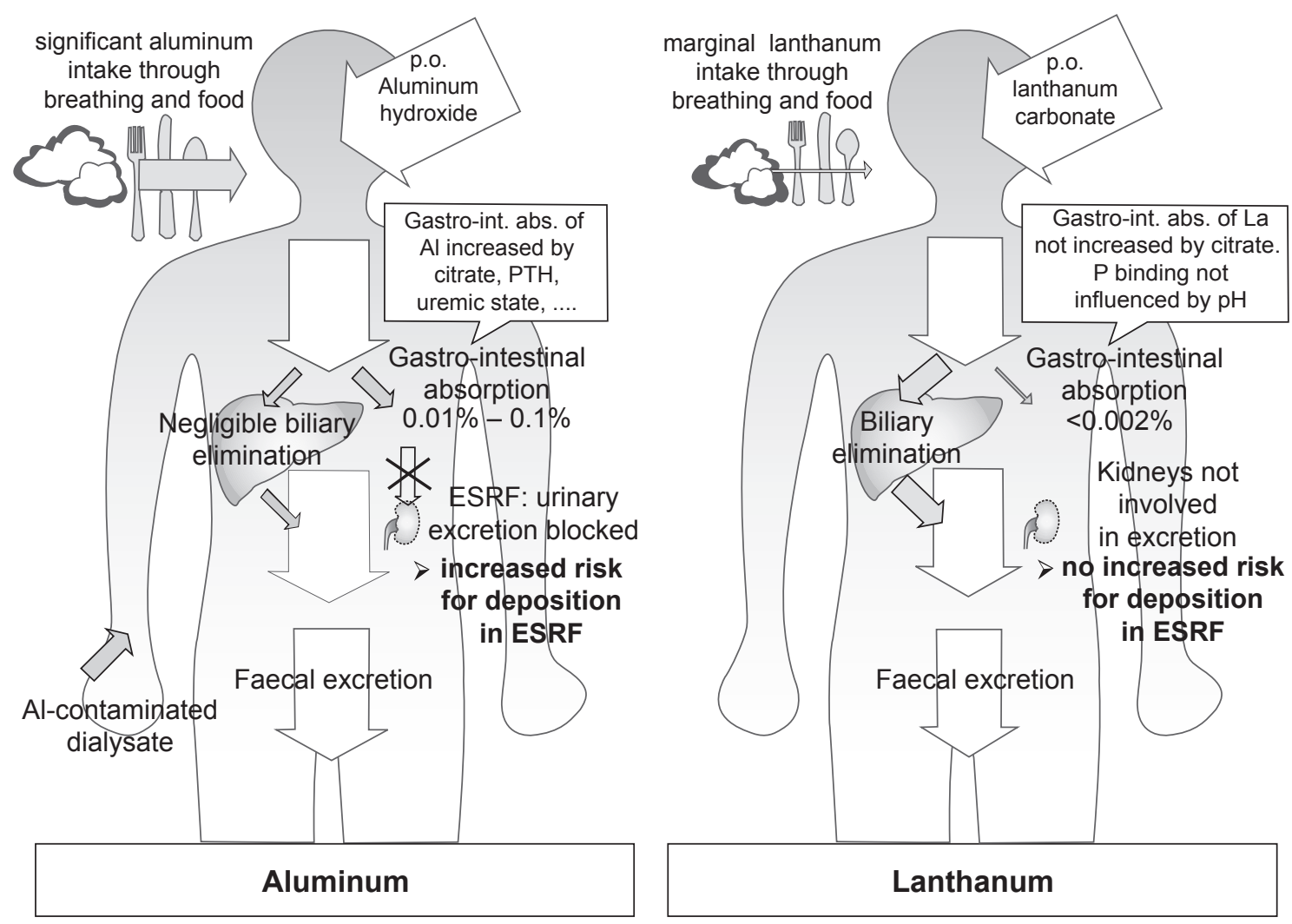

Figure I Comparison of the pharmacokinetics of aluminium and lanthanum. In contrast to aluminium, there is no increased deposition of lanthanum in CKD compared to patients with normal renal function, as the fraction of lanthanum absorbed in the gut is much lower, and lanthanum elimination is independent of renal function as it is mainly eliminated via the bile. Adapted with permission from Persy VP et al. Semin Dial. 2006; 19(3):195-199.59 Copyright (C 2006 Blackwell Publishing. Abbreviations: ESRF, end stage renal failure. 
available for clinical use since 2004 and the additional studies and prolonged follow up described since then indicate that lanthanum carbonate also provides good long-term phosphate control. Follow up data from a 6-month comparative trial with calcium carbonate, showing comparable phosphate control without hypercalcemia under lanthanum carbonate, have been reported after 1 year, ${ }^{40} 3$ years ${ }^{41}$ and recently also after 6 years, ${ }^{42}$ demonstrating adequate and safe long-term phosphate control with lanthanum carbonate. Finn et al demonstrated adequate phosphorus control with PTH levels within the National Kidney Foundation Kidney Disease Outcomes Quality Initiative (K/DOQI) guideline range over a 2-year period. ${ }^{43}$ A double blind RTC comparing lanthanum and calcium carbonate reported similar phosphate control but significantly lower increase in serum calcium in lanthanum treated dialysis patients. ${ }^{44}$

In a placebo-controlled study in CKD 3 and 4 patients, the proprortion of patients achieving serum phosphorus levels $\leq 4.6 \mathrm{mg} / \mathrm{dL}$ was not significantly different between both groups, but serum phosphorus and iPTH levels in lanthanum treated patients were significantly lower. ${ }^{45}$

Lanthanum carbonate being a non-calcium phosphate binder, together with clinical evidence indicating that lanthanum treatment does not induce hypercalcemia and decreases the serum $\mathrm{Ca} \times \mathrm{P}$ product as cited above, gives rise to the hypothesis that lanthanum carbonate treatment may also have a beneficial impact on the progression of vascular calcification. To date, no clinical data on the effect of lanthanum carbonate treatment on vascular calcification have been reported, but in rats with adenine-induced chronic renal failure, treatment with $2 \%$ lanthanum carbonate via the diet attenuated the development of uremia-related vascular calcification. ${ }^{46}$

\section{Effects of lanthanum on bone}

Previous experience with aluminium, which dramatically affected bone health, inducing mainly osteomalacia and adynamic bone disease, prompted concern about the accumulation in and potential toxic effects of lanthanum on bone. In the mean time, extensive research has proven that lanthanum accumulation in bone is limited and does not induce any aluminium-like effects.

In rats with normal renal function long-term administration of lanthanum carbonate at doses up to $2000 \mathrm{mg} / \mathrm{kg}$ per day had no effect on bone, ${ }^{47}$ while loading chronic renal failure rats with lanthanum carbonate doses of 1000 to $2000 \mathrm{mg} / \mathrm{kg}$ per day for 12 weeks induced impairment of bone mineralization. ${ }^{48}$ However, further investigation clearly proved that phosphate depletion induced by high doses of lanthanum carbonate was the mechanism behind this effect on bone. Comparable mineralization defects were observed in rats treated with equivalent doses of sevelamer, ${ }^{49}$ and in rats maintained on a low phosphorus diet. ${ }^{50}$ Moreover, the lanthanum-induced bone effects were normalized by phosphate repletion. ${ }^{50}$ In remnant kidney rats lanthanum carbonate-induced mineralization defect occurred within 2 weeks of treatment, and was rapidly reversible upon lanthanum withdrawal. No correlation between impaired mineralization and bone lanthanum levels was observed, as the bone lanthanum concentration was not yet increased after 2 weeks of treatment and decreased rather slowly after lanthanum withdrawal. ${ }^{51}$

In incipient dialysis patients bone lanthanum concentration rose from $0.05 \pm 0.03$ to $2.3 \pm 1.6 \mu \mathrm{g} / \mathrm{g}$ over a 1 -year treatment period with lanthanum carbonate, while during the subsequent 2 year washout period bone lanthanum levels slightly decreased again to $1.9 \pm 1.6 \mu \mathrm{g} / \mathrm{g} .{ }^{52}$ In prevalent dialysis patients, bone lanthanum levels did not exceed $5.5 \mu \mathrm{g} / \mathrm{g}$ wet weight (median $1.8 \mu \mathrm{g} / \mathrm{g}$ ) after 1 year of treatment with lanthanum carbonate. ${ }^{53}$ In a model of bone lanthanum kinetics based upon data from pharmacokinetic data from healthy volunteers and bone biopsy data from patients treated with lanthanum carbonate for up to 5 years, the initial deposition rate of lanthanum in bone was calculated to be $1 \mu \mathrm{g} / \mathrm{g} / \mathrm{year}$ resulting in an extrapolated 7 -fold increase in total bone lanthanum after 10 years of treatment. This model further predicts lanthanum clearance from bone at a rate of $13 \%$ per year after cessation of treatment. ${ }^{54}$

Two clinical studies document the absence of adverse effects of lanthanum carbonate treatment on bone histology. ${ }^{53,55}$ In a randomized, parallel-group, open-label study the evolution of renal osteodystrophy (ROD) in dialysis patients receiving either lanthanum carbonate or calcium carbonate was compared after histomorphometric examination of paired bone biopsies $^{53}$ after 1 year of treatment. While baseline bone histology was comparable between both groups with mixed ROD as the most common type of bone lesion, 1 year of lanthanum carbonate treatment tended to normalize bone histology, with reduced prevalence of the more extreme forms of ROD (hyperparathyroidism, adynamic bone disease and osteomalacia). Calcium carbonate treatment was associated with an increase in the proportion of patients with hyperparathyroidism or adynamic bone disease. Overall, 5 out of $7(71 \%)$ of lanthanum carbonate-treated patients with low-turnover bone disease (adynamic bone or osteomalacia) at baseline, and $80 \%$ (4 out of 5) of those with baseline 
hyperparathyroidism evolved towards a normalization in bone turnover, compared with 3 out of 7 (42\%) and 3 out of $6(50 \%)$ of calcium carbonate-treated patients, respectively. ${ }^{53}$ In a prospective, open-label study during which patients on dialysis were randomized to lanthanum carbonate treatment or continuation of their previous phosphate binder, a significant improvement in bone turnover after 1 year and in bone volume after 2 years of treatment was seen in the lanthanum carbonate group, whereas these parameters remained unchanged in patients treated with standard phosphate binder therapy. Bone histomorphometric parameters did not correlate with bone lanthanum concentrations. ${ }^{55}$

In contrast to aluminium-related bone disease which is characterized by decreased osteoblast number and/or activity, ${ }^{56}$ no adverse effect of lanthanum carbonate on osteoblasts has been observed in either rats or humans. In contrast, Wang et al recently reported that lanthanum promoted osteoblast differentiation in vitro, resulting in increased expression of osteoblast differentiation factors such as core binding factor-1 (cbfa-1), alkaline phosphatase, osteopontin, bone sialoprotein and osteocalcin, as well as increased matrix mineralization. ${ }^{57}$ This effect was mediated by increased phosphorylation of extracellular signal-related kinase (ERK). ${ }^{57}$

Toxic effects strongly depend on local concentrations in target tissue and cells, whereas physicochemical interference with mineralization on the level of hydroxyapatite nucleation, crystal growth or structure strongly depends on the molar ratio of an element over calcium. Lanthanum localization studies have not revealed any indication that lanthanum would selectively concentrate at particular sites or cell types in bone. Localization of lanthanum carbonate in bone with micro X-ray fluorescence demonstrated the presence of lanthanum at both active and quiescent trabecular surface, independent of the type of underlying ROD. In addition, lanthanum could be detected distributed diffusely throughout the mineralized matrix, especially in subjects with increased bone turnover, and concentrated close to resorption lacunae, probably in osteoclasts or macrophages (Figure 2). ${ }^{58}$

Additionally, based upon a bone lanthanum concentration of $9.5 \mu \mathrm{g} / \mathrm{g}$ wet weight $(67 \mathrm{nmol} / \mathrm{g})$ - the highest lanthanum concentration observed in the bone of dialysis patients after 4.5 years of treatment with 2.5 to $3.0 \mathrm{~g}$ lanthanum/day - with bone calcium concentration at $120 \mathrm{mg} / \mathrm{g}(3 \mathrm{mmol} / \mathrm{g})$ and assuming a homogeneous distribution of lanthanum throughout the bone, the molar bone lanthanum/calcium ratio would be as low as $2 \times 10^{-5}$, ie, only 1 out of 50,000 calcium atoms would be replaced by lanthanum, making physicochemical

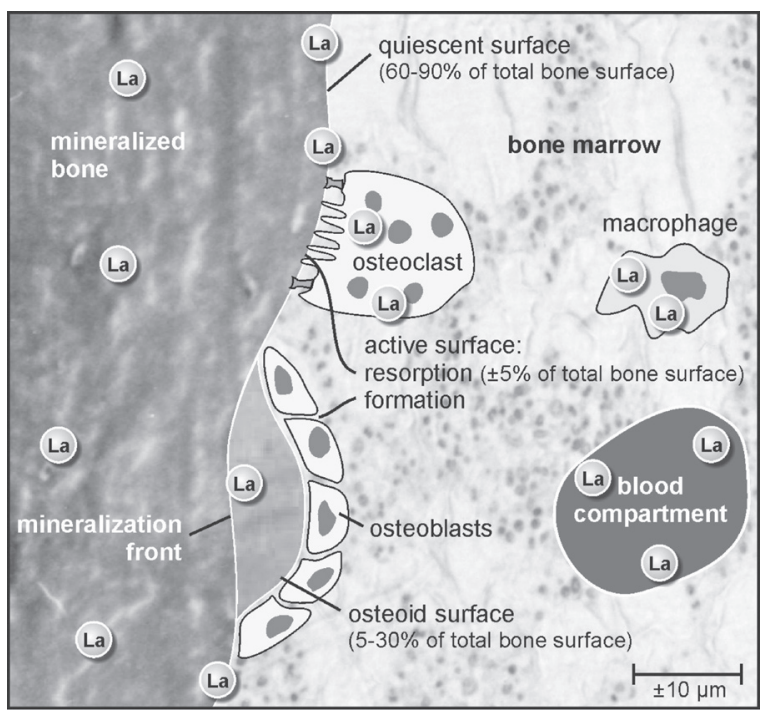

Figure 2 Schematic representation of lanthanum localization in bone. With micro $\mathrm{X}$-ray fluorescence, lanthanum was found at active bone formation and resorption sites, as well as on quiescent bone surfaces and dispersed throughout the mineralized matrix. Lanthanum concentrations in proximity to resorption lacunae probably reflect lanthanum uptake in osteoclasts or macrophages. ${ }^{58} \mathrm{Adapted}$ with permission from Persy VP et al. Semin Dial. 2006;19(3):195-199.59 Copyright (C) 2006 Blackwell Publishing.

interference of lanthanum ions incorporated into the bone matrix with the mineralization process highly unlikely. For comparison, according to the same premisses the molar aluminium/calcium ratio was estimated at $6 \times 10^{-2}$, indicating that 1 out of 16 calcium atoms would be replaced by aluminium. ${ }^{59}$

\section{Effects of lanthanum on the liver}

In addition to bone, lanthanum deposition is also detected in the liver. This is not surprising, as lanthanum is mainly excreted via the hepatobiliary pathway (Figure 1). Hence, CKD patients are not expected to be at an increased risk for accumulation of lanthanum in comparison with subjects with normal renal function.

In line with these expectations, clinical experience with lanthanum carbonate as a phosphate binder up to now provided no indications for any hepatotoxic effect of this compound. ${ }^{42}$ Over 6 years of follow up, liver enzymes did not increase and the limited number of liver or biliary related adverse events were mainly observed in the first 2 years of treatment and none of them were considered to be related to lanthanum treatment. ${ }^{42}$

However, increased liver lanthanum deposition after oral lanthanum loading in uremic rats in comparison with normal renal function rats was observed in two different experimental models of chronic renal failure. ${ }^{60,61}$ After intravenous 
lanthanum administration, liver lanthanum concentrations were independent of renal function, indicating comparable lanthanum elimination, and indirectly pointing towards increased absorption of lanthanum from the gastrointestinal tract as explanation for differences in liver tissue deposition in normal versus uremic rats. ${ }^{62}$ Oral lanthanum carbonate loading ( $1000 \mathrm{mg} / \mathrm{kg}$ per day -6 days per week) of rats with moderately impaired renal function resulted in liver lanthanum concentrations consistently below $3 \mu \mathrm{g} / \mathrm{g}$ reaching a plateau after 6 weeks of lanthanum treatment, ${ }^{62}$ indicating that a steady state of liver lanthanum concentration is reached at that time point.

To enable subcellular localization of lanthanum in liver tissue, rats received daily intravenous injections with $0.3 \mathrm{mg} / \mathrm{kg}$ lanthanum chloride for 4 weeks, leading to liver lanthanum concentrations of 30 to $50 \mu \mathrm{g} / \mathrm{g}$ (10- to 20-fold higher than values seen after oral lanthanum loading). Sensitive techniques such as transmission electron microscopy (TEM), Energy dispersive X-ray analysis (EDX) and electron loss spectroscopy (EELS) were used to demonstrate that lanthanum in the liver of these animals was present in the lysosomes of hepatocytes, with most of the lanthanum concentrated in the biliary pole of the hepatocyte and within bile canaliculi. No lanthanum could be detected in hepatocyte mitochondria, nucleus or cytoplasm (Figure 3 ). ${ }^{63}$

\section{Lanthanum and brain}

In contrast to aluminium, lanthanum does not pass the blood-brain barrier. In several experimental studies, lanthanum concentrations in the brain after intravenous lanthanum dosing at 30 to $300 \mathrm{mg} / \mathrm{kg} /$ day for 4 weeks or oral gavage at $1500 \mathrm{mg} / \mathrm{kg} /$ day were below the limit of quantification, ie, $<6 \mathrm{ng} / \mathrm{g}$.

Assessment of cognitive function of patients after 2 years of treatment in a randomized open-label study comparing lanthanum carbonate with standard treatment revealed that cognitive function deteriorated with time in both groups. Overall cognitive function was comparable between both treatments, with lanthanum-treated patients showing a small

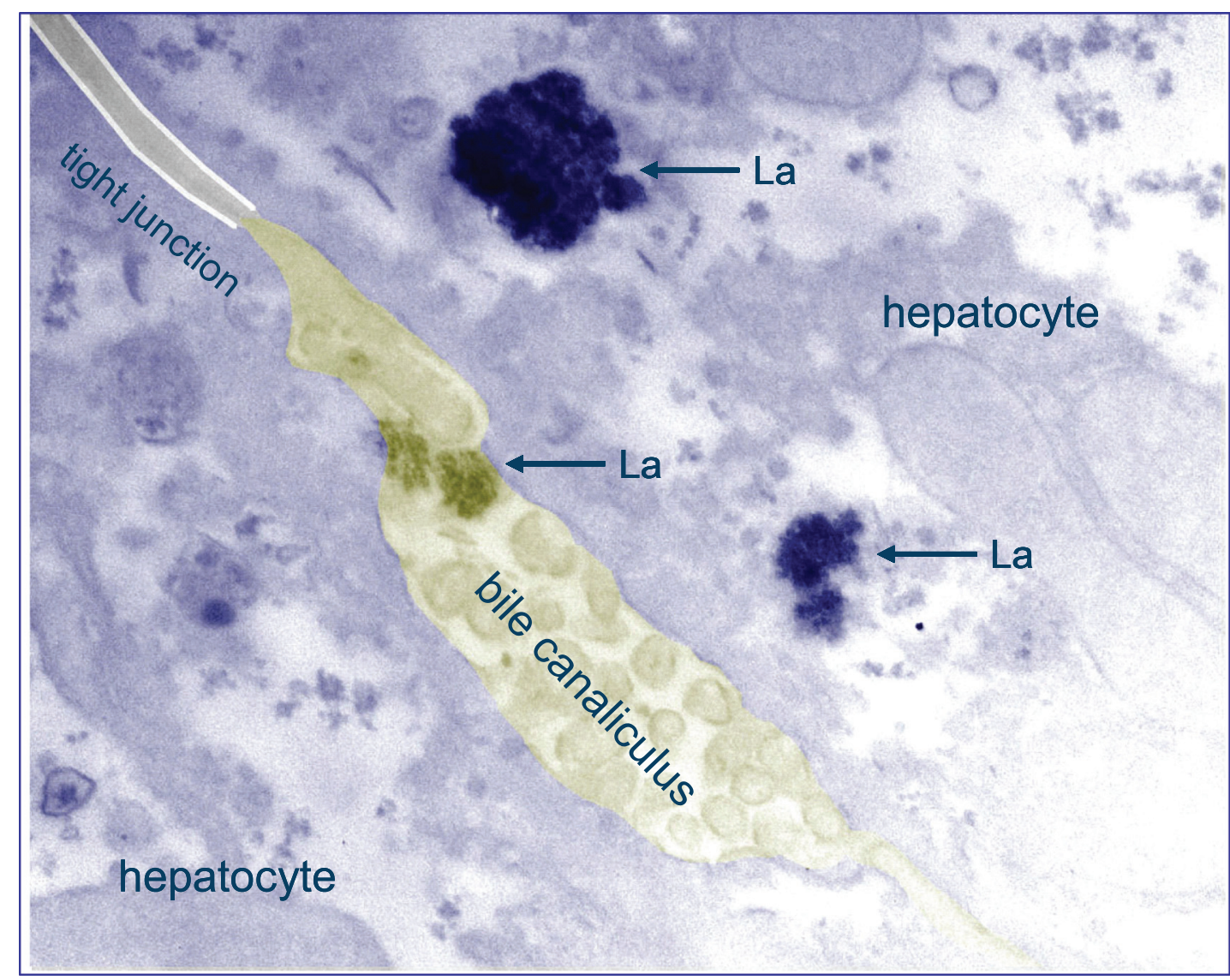

Figure 3 Lanthanum is localized in lysosomes at the biliary pole of hepatocytes. Transmission electron microscopy image of liver tissue of La loaded rat (dose: $0.3 \mathrm{mg} / \mathrm{kg} / \mathrm{day}$ IV, 4 weeks) showing electron dense precipitates displaying a crystalline granular structure within the lysosomes and bile canaliculus. The presence of lanthanum in these granular structures was evidenced by electron energy loss spectroscopy (EELS). Adapted with permission from Macmillan Publishers, Ltd. Kidney Int. Bervoets AR, Behets G], Schryvers D, et al. 2009;75(4):389-398. Copyright @ 2008. ${ }^{62}$ 
but significant improvement in numeric working memory, of which the clinical significance remains to be determined. ${ }^{64}$

\section{Summary}

Clinical data for up to 6 years of follow-up indicate that lanthanum carbonate is an effective and safe non-calcium phosphate binder. Concerns about aluminium-like toxicity of lanthanum carbonate have effectively been countered by (i) pharmacokinetic studies indicating that lanthanum is mainly eliminated via the liver, (ii) bone studies showing heterogeneous localization of lanthanum in bone and the absence of adverse effects on bone histology in lanthanum-treated patients, (iii) no adverse effect of lanthanum treatment on cognitive functioning and absence of lanthanum deposition in brain tissue.

\section{Disclosures}

Patrick C D'Haese and Marc E De Broe are members of the Scientific Advisory Board and received grants/research support for conducting some of their studies related to lanthanum carbonate from Shire Pharmaceutical Development Ltd.

\section{References}

1. Silver J, Kilav R, Naveh-Many T. Mechanisms of secondary hyperparathyroidism. Am J Physiol Renal Physiol. 2002;283(3):F367-F376.

2. Craver L, Marco MP, Martinez I et al. Mineral metabolism parameters throughout chronic kidney disease stages 1-5 - achievement of K/DOQI target ranges. Nephrol Dial Transplant. 2007;22(4):1171-1176.

3. Block GA, Hulbert-Shearon TE, Levin NW, Port FK. Association of serum phosphorus and calcium $\mathrm{x}$ phosphate product with mortality risk in chronic hemodialysis patients: a national study. Am J Kidney Dis 1998;31(4):607-617.

4. Kestenbaum B, Sampson JN, Rudser KD, et al. Serum Phosphate Levels and Mortality Risk among People with Chronic Kidney Disease. J Am Soc Nephrol. 2005;16(2):520-528.

5. Ganesh SK, Stack AG, Levin NW, Hulbert-Shearon T, Port FK. Association of elevated serum $\mathrm{PO}(4), \mathrm{Ca} \times \mathrm{PO}(4)$ product, and parathyroid hormone with cardiac mortality risk in chronic hemodialysis patients. $J$ Am Soc Nephrol. 2001;12(10):2131-2138.

6. Jono S, McKee MD, Murry CE, et al. Phosphate regulation of vascular smooth muscle cell calcification. Circ Res. 2000;87(7):E10-E17.

7. Li X, Yang HY, Giachelli CM. Role of the sodium-dependent phosphate cotransporter, Pit-1, in vascular smooth muscle cell calcification. Circ Res. 2006;98(7):905-912.

8. Okuno S, Ishimura E, Kitatani K, et al. Presence of abdominal aortic calcification is significantly associated with all-cause and cardiovascular mortality in maintenance hemodialysis patients. Am J Kidney Dis. 2007;49(3):417-425.

9. Wilson PW, Kauppila LI, O’Donnell CJ, et al. Abdominal aortic calcific deposits are an important predictor of vascular morbidity and mortality. Circulation. 200120;103(11):1529-1534.

10. Kopple JD. Effect of nutrition on morbidity and mortality in maintenance dialysis patients. Am J Kidney Dis. 1994;24(6):1002-1009.

11. Goldwasser P, Mittman N, Antignani A, et al. Predictors of mortality in hemodialysis patients. J Am Soc Nephrol. 1993;3(9):1613-1622.

12. Cianciaruso B, Pota A, Pisani A, et al. Metabolic effects of two low protein diets in chronic kidney disease stage 4-5 - a randomized controlled trial. Nephrol Dial Transplant. 2008;23(2):636-644.
13. Pohlmeier R, Vienken J. Phosphate removal and hemodialysis conditions. Kidney Int Suppl. 2001;78:S190-S194.

14. Leypoldt JK. Kinetics of beta2-microglobulin and phosphate during hemodialysis: effects of treatment frequency and duration. Semin Dial. 2005;18(5):401-408.

15. Sheikh MS, Maguire JA, Emmett M, et al. Reduction of dietary phosphorus absorption by phosphorus binders. A theoretical, in vitro, and in vivo study. J Clin Invest. 1989;83(1):66-73.

16. Mai ML, Emmett M, Sheikh MS, Santa Ana CA, Schiller L, Fordtran JS Calcium acetate, an effective phosphorus binder in patients with renal failure. Kidney Int. 1989;36(4):690-695.

17. Chertow GM, Raggi P, Chasan-Taber S, Bommer J, Holzer H, Burke SK Determinants of progressive vascular calcification in haemodialysis patients. Nephrol Dial Transplant. 2004;19(6):1489-1496.

18. Goldsmith DJ, Covic A, Sambrook PA, Ackrill P. Vascular calcification in long-term haemodialysis patients in a single unit: a retrospective analysis. Nephron. 1997;77(1):37-43.

19. Goodman WG, Goldin J, Kuizon BD et al. Coronary-artery calcification in young adults with end-stage renal disease who are undergoing dialysis. $N$ Engl J Med. 2000;342(20):1478-1483.

20. London GM, Guerin AP, Marchais SJ, Metivier F, Pannier B, Adda H Arterial media calcification in end-stage renal disease: impact on all-cause and cardiovascular mortality. Nephrol Dial Transplant. 2003;18(9):1731-1740.

21. Raggi P, Boulay A, Chasan-Taber S, et al. Cardiac calcification in adult hemodialysis patients. A link between end-stage renal disease and cardiovascular disease? J Am Coll Cardiol. 2002;20; 39(4):695-701.

22. Chertow GM, Burke SK, Raggi P. Sevelamer attenuates the progression of coronary and aortic calcification in hemodialysis patients. Kidney Int. 2002;62(1):245-252.

23. Block GA, Spiegel DM, Ehrlich J, et al. Effects of sevelamer and calcium on coronary artery calcification in patients new to hemodialysis. Kidney Int. 2005;68(4):1815-1824.

24. Izumi M, Morita S, Nishian Y, et al. Switching from calcium carbonate to sevelamer hydrochloride has suppressive effects on the progression of aortic calcification in hemodialysis patients: assessment using plain chest X-ray films. Ren Fail. 2008;30(10):952-958.

25. Takei T, Otsubo S, Uchida K, et al. Effects of sevelamer on the progression of vascular calcification in patients on chronic haemodialysis Nephron Clin Pract. 2008;108(4):c278-c283.

26. Barreto DV, Barreto FD, de Carvalho AB, et al. Phosphate Binder Impact on Bone Remodeling and Coronary Calcification - Results from the BRiC Study. Nephron Clin Pract. 2008;110(4):c273-c283.

27. Braunlin W, Zhorov E, Guo A, et al. Bile acid binding to sevelamer HCl. Kidney Int. 2002;62(2):611-619.

28. Marco MP, Muray S, Betriu A, Craver L, Belart M, Fernandez E. Treatment with sevelamer decreases bicarbonate levels in hemodialysis patients. Nephron. 2002;92(2):499-500.

29. Brezina B, Qunibi WY, Nolan CR. Acid loading during treatment with sevelamer hydrochloride: mechanisms and clinical implications. Kidney Int Suppl. 2004;(90):S39-S45.

30. Sprague SM. A comparative review of the efficacy and safety of established phosphate binders: calcium, sevelamer, and lanthanum carbonate. Curr Med Res Opin. 2007;23(12):3167-3175.

31. Pennick M, Dennis K, Damment SJ. Absolute bioavailability and disposition of lanthanum in healthy human subjects administered lanthanum carbonate. J Clin Pharmacol. 2006;46(7):738-746.

32. Pennick M, Dennis K, Damment SJ. Absolute bioavailability and disposition of lanthanum in healthy human subjects administered lanthanum carbonate. J Clin Pharmacol. 2006;46(7):738-746.

33. Damment SJ, Pennick M. Clinical pharmacokinetics of the phosphate binder lanthanum carbonate. Clin Pharmacokinet. 2008;47(9):553-563.

34. Jouhanneau P, Raisbeck GM, Yiou F, Lacour B, Banide H, Drueke TB. Gastrointestinal absorption, tissue retention, and urinary excretion of dietary aluminium in rats determined by using 26Al. Clin Chem. 1997;43(6 Pt 1):1023-1028. 
35. Coburn JW, Mischel MG, Goodman WG, Salusky IB. Calcium citrate markedly enhances aluminium absorption from aluminium hydroxide. Am J Kidney Dis. 1991;17(6):708-711.

36. Autissier V, Damment SJ, Henderson RA. Relative in vitro efficacy of the phosphate binders lanthanum carbonate and sevelamer hydrochloride 1. J Pharm Sci. 2007;96(10):2818-2827.

37. Joy MS, Finn WF. Randomized, double-blind, placebo-controlled, dose-titration, phase III study assessing the efficacy and tolerability of lanthanum carbonate: a new phosphate binder for the treatment of hyperphosphatemia. Am J Kidney Dis. 2003;42(1):96-107.

38. Al-Baaj F, Speake M, Hutchison AJ. Control of serum phosphate by oral lanthanum carbonate in patients undergoing haemodialysis and continuous ambulatory peritoneal dialysis in a short-term, placebo-controlled study. Nephrol Dial Transplant. 2005;20(4):775-782.

39. Chiang SS, Chen JB, Yang WC. Lanthanum carbonate (Fosrenol) efficacy and tolerability in the treatment of hyperphosphatemic patients with end-stage renal disease. Clin Nephrol. 2005;63(6):461-470.

40. Hutchison AJ, Maes B, Vanwalleghem J, et al. Efficacy, tolerability, and safety of lanthanum carbonate in hyperphosphatemia: a 6-month, randomized, comparative trial versus calcium carbonate. Nephron Clin Pract. 2005;100(1):c8-19.

41. Hutchison AJ, Maes B, Vanwalleghem J, et al. Long-term efficacy and tolerability of lanthanum carbonate: results from a 3-year study. Nephron Clin Pract. 2006;102(2):c61-c71.

42. Hutchison AJ, Barnett ME, Krause R, Kwan JT, Siami GA. Long-term efficacy and safety profile of lanthanum carbonate: results for up to 6 years of treatment. Nephron Clin Pract. 2008;110(1):c15-c23.

43. Finn WF. Lanthanum carbonate versus standard therapy for the treatment of hyperphosphatemia: safety and efficacy in chronic maintenance hemodialysis patients. Clin Nephrol. 2006;65(3):191-202.

44. Shigematsu T. Lanthanum carbonate effectively controls serum phosphate without affecting serum calcium levels in patients undergoing hemodialysis. Ther Apher Dial. 2008;12(1):55-61.

45. Sprague SM, Abboud H, Qiu P, Dauphin M, Zhang P, Finn W. Lanthanum Carbonate Reduces Phosphorus Burden in Patients with CKD Stages 3 and 4: A Randomized Trial. Clin J Am Soc Nephrol. 2009;4(1):178-185.

46. Neven E, Dams G, Postnov A, et al. Adequate phosphate binding with lanthanum carbonate attenuates arterial calcification in chronic renal failure rats. Nephrol Dial Transplant. 2009; Jan 14 [Epub ahead of print]. doi:10.1093/ndt/gfn 737.

47. Damment SJP, Greaves P, Downes N. The toxicology of lanthanum carbonate (Fosrenol), a new non-aluminium, non-calcium phosphate binder [abstract]. J Am Soc Nephrol. 2003;14:204A.

48. Behets GJ, Dams G, Vercauteren SR, et al. Does the phosphate binder lanthanum carbonate affect bone in rats with chronic renal failure? $\mathrm{J} \mathrm{Am}$ Soc Nephrol. 2004;15(8):221922-28.

49. Behets GJ, Gritters M, Dams G, De Broe ME, D'Haese PC. Effects of efficient phosphate binding on bone in chronic renal failure rats. Ren Fail. 2005;27(4):475-484.
50. Damment SJ, Shen V. Assessment of effects of lanthanum carbonate with and without phosphate supplementation on bone mineralization in uremic rats. Clin Nephrol. 2005;63(2):127-137.

51. Bervoets AR, oste L, Behets GJ, et al. Development and reversibility of impaired mineralization associated with lanthanum carbonate treatment in chronic renal failure rats. Bone. 2006;38(6):803-810.

52. Spasovski GB, Sikole A, Gelev S, et al. Evolution of bone and plasma concentration of lanthanum in dialysis patients before, during 1 year of treatment with lanthanum carbonate and after 2 years of follow-up. Nephrol Dial Transplant. 2006;21(8):2217-2224.

53. D'Haese PC, Spasovski GB, Sikole A, et al. A multicenter study on the effects of lanthanum carbonate (Fosrenol) and calcium carbonate on renal bone disease in dialysis patients. Kidney Int Suppl. 2003;(85):S73-S78.

54. Bronner F, Slepchenko BM, Pennick M, Damment SJ. A model of the kinetics of lanthanum in human bone, using data collected during the clinical development of the phosphate binder lanthanum carbonate. Clin Pharmacokinet. 2008;47(8):543-552.

55. Malluche HH, Siami GA, Swanepoel C, et al. Improvements in renal osteodystrophy in patients treated with lanthanum carbonate for two years. Clin Nephrol. 2008;70(4):284-295.

56. Rodriguez M, Felsenfeld AJ, Llach F. Aluminium administration in the rat separately affects the osteoblast and bone mineralization. $J$ Bone Miner Res. 1990;5(1):59-67.

57. Wang X, Yuan L, Huang J, Zhang TL, Wang K. Lanthanum enhances in vitro osteoblast differentiation via pertussis toxin-sensitive gi protein and ERK signaling pathway. J Cell Biochem. 2008105(5):1307-1315.

58. Behets GJ, Verberckmoes SC, oste L, et al. Localization of lanthanum in bone of chronic renal failure rats after oral dosing with lanthanum carbonate. Kidney Int. 2005;67(5):1830-1836.

59. Persy VP, Behets GJ, Bervoets AR, De Broe ME, D'Haese PC. Lanthanum: a safe phosphate binder. Semin Dial. 2006;19(3):195-199.

60. Slatopolsky E, Liapis H, Finch J. Progressive accumulation of lanthanum in the liver of normal and uremic rats. Kidney Int. 2005;68(6):2809-2813.

61. Lacour B, Lucas A, Auchere D, Ruellan N, Serre Patey NM, Drueke TB. Chronic renal failure is associated with increased tissue deposition of lanthanum after 28-day oral administration. Kidney Int. 2005;67(3): 1062-1069.

62. Bervoets AR, Behets GJ, Schryvers D, et al. Hepatocellular transport and gastrointestinal absorption of lanthanum in chronic renal failure. Kidney Int. 2008;75:389-398.

63. Yang Z, Schryvers D, Roels F, D'Haese PC, De Broe ME. Demonstration of lanthanum in liver cells by energy-dispersive X-ray spectroscopy, electron energy loss spectroscopy and high-resolution transmission electron microscopy. J Microsc. 2006;223(Pt 2):133-139.

64. Altmann P, Barnett ME, Finn WF. Cognitive function in Stage 5 chronic kidney disease patients on hemodialysis: no adverse effects of lanthanum carbonate compared with standard phosphate-binder therapy. Kidney Int. 2007;71(3):252-259. 